\title{
Overdissipation and convergence in rent-seeking experiments: Cost structure and prize allocation rules ${ }^{1}$
}

\author{
Subhasish M. Chowdhury ${ }^{2}$ \\ Roman M. Sheremeta ${ }^{3}$ \\ University of East Anglia \\ Chapman University \\ Theodore L. Turocy ${ }^{4}$ \\ University of East Anglia
}

May 2, 2012

\footnotetext{
${ }^{1}$ We appreciate the helpful comments of Klaus Abbink, Dan Levin, Phillip Reiss, Karl Wärneryd, participants at the 4th Maastricht Behavioral and Experimental Economics Symposium and seminar participants at the University of Gottingen, the University of St Gallen, and Stockholm School of Economics. This research has been supported by a grant from the Centre for Behavioural and Experimental Social Science at the University of East Anglia. Any remaining errors are ours.

${ }^{2}$ Corresponding author, School of Economics, Centre for Behavioural and Experimental Social Science, and ESRC Centre for Competition Policy, University of East Anglia, Norwich NR4 7TJ, UK, Email: s.modak-chowdhury@uea.ac.uk

${ }^{3}$ Argyros School of Business and Economics, Chapman University, One University Drive, Orange, CA 92866, U.S.A.

${ }^{4}$ School of Economics, and Centre for Behavioural and Experimental Social Science, University of East Anglia, Norwich NR4 7TJ, UK
} 


\begin{abstract}
We study experimentally the effects of cost structure and prize allocation rules on the performance of rent-seeking contests. Most previous studies use a lottery prize rule and linear cost, and find both overdissipation relative to Nash equilibrium prediction and significant variation in individual subject efforts. In a $2 \times 2$ design, we investigate the effects of sharing the prize proportionally and of a convex cost function, while holding fixed the Nash equilibrium prediction for effort. We find that the share rule results in average effort closer to the Nash prediction, lower variation in individual efforts, and convergence of the distribution of individual efforts towards Nash over time. Combining the share rule with a convex cost function further enhances these results. Our findings indicate that a significant amount of subjects' non-equilibrium behavior in contests can be explained by features of the experimental design. These results contribute towards design guidelines for contests based on behavioral principles that take into account contest features that may not affect the Nash equilibrium prediction.
\end{abstract}

These lessons suggest design guidelines for future experiments on contests.

JEL Classifications: C72, C91, D72

Keywords: rent-seeking, contest, contest design, experiments, quantal response, over-dissipation 


\section{Introduction}

Overdissipation in rent-seeking contests (Tullock, 1980) is a robust result in the experimental literature. This phenomenon was first reported in experimental contest studies by Millner and Pratt (1989, 1991) and has since been replicated by many other experiments, including, among others, Davis and Reilly (1998), Potters et al. (1998), Lim et al. (2011), Sheremeta (2010a), Sheremeta (2010b), Sheremeta (2011), and Sheremeta and Zhang (2010). Average effort levels in contests exceed the Nash equilibrium prediction, in some cases by a wide enough margin that total expenditure by all contest participants exceeds the value of the prize. Moreover, contrary to the theoretical prediction of a unique pure strategy Nash equilibrium, experimental studies document that individual efforts are distributed on the entire strategy space, and even aggregate individual behavior is heterogeneous. We refer to this stylized fact as "overspreading."

Over the last decade a number of studies have offered different explanations for overdissipation and overspreading in rent-seeking contests. Commonly cited explanations for overdissipation are: (1) noise and errors (Schmidt et al., 2005; Lim et al., 2011; Sheremeta, 2011), (2) judgmental biases (Amaldoss and Rapoport, 2009; Sheremeta, 2011), (3) a non-monetary utility of winning (Sheremeta, 2010a,b; Price and Sheremeta, 2011), and (4) evolutionary stable behavior (Mago et al., 2012; Wärneryd, 2012). Overspreading (substantial variation in individual behavior) is usually attributed to heterogeneity in subjects' preferences over factors such as (1) loss aversion (Kong, 2008), (2) risk aversion (Sheremeta, 2011), (3) spitefulness (Herrman and Orzen, 2008), and (4) preferences towards winning (Sheremeta, 2010a,b).

Although there are many studies investigating what factors can explain subjects' non-equilibrium behavior in contests, there are virtually no studies that investigate particular experimental design features that may trigger such behavior. In a standard lottery contest, all players exert effort in order to increase their probability of winning the prize. Higher efforts imply higher probability of winning, but they are also more costly. In equilibrium, the marginal benefit of effort is equal to the marginal cost. Therefore, a correct best-response computation requires experimental subjects to assess correctly marginal benefit, which depends on the probability of winning, and marginal cost, which depends on the convexity of the cost function. Any non-equilibrium behavior may thus simply come as a consequence of a difficult computational task (Wright, 1980; Simon, 1992; Rubenstein, 1998; Gigrenzer and Selten, 2001).

It has been well recognized, for example, that subjects possess distored perceptions of probabilities, which may lead to non-equilibrium behavior. As a consequence, many alternative theories have been proposed to account for such perceptions (Kahneman and Tversky, 1979; Quiggin, 1982; Chew, 1983; Tversky and Kahneman, 1992; Wilcox, 2011). Recent studies have tried to apply some of these theories to explain subject behavior in contests and auctions (Goeree et al., 2002; 
Baharad and Nitzan, 2008; Amaldoss and Rapoport, 2009). However, even after accounting for individual perceptions of probabilities, the aggregate patterns of overdissipation and overspreading lottery contests cannot be explained. ${ }^{1}$

Another explanation for why subjects' behavior differs from theoretical predictions is based on flatness of payoff functions (Harrison, 1989; Goeree et al., 2002; Georganas et al., 2011). Harrison (1989), for instance, argues that overbidding in private value auctions relative to the Nash equilibrium may be due to the fact that the costs of such overbidding are rather small. By manipulating the cost of overbidding in the first-price and second-price winner pay auctions, Goeree et al. (2002) and Georganas et al. (2011) find support for this argument. Similarly, Müller and Schotter (2010) find that subjects overbid in the private value all-pay contests when the cost of bid function is linear but they actually underbid when the cost function is convex.

These findings suggest that there may be certain features of experimental design, such as cost structure and prize sharing rules that influence individual behavior in contests. To test these hypotheses, we investigate the effects of sharing the prize proportionally and of a convex cost function in a $2 \times 2$ design while holding fixed the Nash equilibrium. We find that in contests where the prize is shared proportionally, average efforts are closer to the Nash equilibrium prediction, there is lower variation in individual efforts, and efforts converge towards the Nash equilibrium over time. A convex cost function enhances these results under the share rule; however, we find that convex costs actually exacerbate overdissipation with probabilistic allocation, which we attribute to knock-on effects driven by out-of-equilibrium play. These findings illustate the importance of considering the behavioral drivers of out-of-equilibrium play for robust design of contests, and provide some first results for guidance of contest design along these lines.

\section{Theoretical background}

We study a rent-seeking contest game following Tullock (1980). There are $N$ players, indexed by $i$. There is a prize, worth $V>0$. Each player $i$ simultaneously chooses an effort level $e_{i} \in[0, V]$. In a standard abuse of notation, we will write $e_{-i}=\sum_{j \neq i} e_{j}$ to denote the sum of efforts of other players. The cost of effort is given by a function $c: \mathbb{R}_{+} \rightarrow \mathbb{R}_{+}$, which we assume to be continuous, monotonically increasing, and twice differentiable in effort. Irrespective of the outcome of the contest, all players forgo the cost of effort.

\footnotetext{
${ }^{1}$ For example, Hillman and Katz (1984) and Skaperdas and Gan (1995) show that a simple assumption, as in Pratt (1964), about risk aversion should lead to lower, not higher, aggregate efforts than risk neutrality.
} 
The contest success function is given by

$$
p_{i}\left(e_{i}, e_{-i}\right)= \begin{cases}\frac{e_{i}}{e_{i}+e_{-i}} & \text { if } e_{i}+e_{-i}>0 \\ \frac{1}{N} . & \text { otherwise }\end{cases}
$$

This function can be interpreted as either the probability that player $i$ wins the prize, if it is allocated indivisibly to just one player, or the proportion of the prize awarded to player $i$. In either case, the expected payoff to player $i$ can be written as

$$
E\left(\pi_{i}\right)=p_{i} V-c\left(e_{i}\right)
$$

When the prize is shared proportionally, there is no uncertainty in the outcome of the contest, and this amounts to assuming that players maximize expected monetary payoffs. When the prize is allocated via a lottery, this further assumes risk neutrality among players. Szidarovszky and Okuguchi (1997) show the existence and uniqueness of equilibrium of this game, where the equilibrium effort level $e^{\star}$ is given by the solution to the equation

$$
c^{\prime}\left(e^{\star}\right) e^{\star}=V \frac{(N-1)}{N^{2}} .
$$

\section{Experimental Design and Procedures}

We implemented a two-dimensional factorial design. In one dimension, we varied the contest success function, using the probabilistic $(P)$ or share $(S)$ rules for awarding the prize. In the second dimension, we varied the cost function, using the standard linear $(L)$ cost function or a convex $(C)$ cost function. We therefore had four treatments, labeled $P L, P C, S L$, and $S C$.

In each treatment, we conducted 3 independent sessions. Sessions consisted of 12 participants, who participated in 30 contests. Each session investigated only one treatment, so all comparisons are across subjects. All sessions used student subjects at the Centre for Behavioural and Experimental Social Science at University of East Anglia. The computerized experimental sessions were run using z-Tree (Fischbacher, 2007).

Participants were matched into groups of $N=4$, with random anonymous rematching after each contest. The value of the prize in all contests was $V=80$ experimental francs. In each contest, participants simultaneously selected an effort level between 0 and 80 . In sessions employing the linear cost function, the cost of effort was $c(e)=e$. In sessions with the convex cost function, the cost function $c(e)=\frac{e^{2}}{30}$ was used. Both cost functions lead to an equilibrium prediction for effort of $e^{\star}=15$. At the conclusion of the experiment, 5 of the 30 periods were chosen at random 
for payment. The earnings were converted into British pounds at the rate of 40 francs to $£ 1$. All subjects also received a participation fee of $£ 15$ to cover potential losses. Subjects were informed about the group size, prize value, and the cost structure. After each round, information on own and group effort, win or loss outcome and own payoff in that round was provided.

In both the linear and convex cost treatments, the choice variable for participants was the amount of effort, as opposed to the cost of effort. We made this decision to ensure comparability of the strategy space between the treatments. We conveyed information about the relationship between effort choices and costs by means of a table in the instructions ${ }^{2}$ enumerating each effort choice and its corresponding cost. In the linear cost case, this device adds a small additional complexity not present in most contest experiments, and, as participants only saw either the linear or convex cost treatments, the use of such a table may have seemed unusual to participants in those treatments. In our analysis we confirm that we replicate results from a previous contest experiment to rule out the concern this device may have affected behaviour. In the convex cost case, the use of the table device permitted participants, in principle, to make decisions either based on the amount of effort to invest, or the amount of cost of effort. We therefore did not pursue a treatment in which cost rather than effort was framed as the decision variable.

\section{Results}

Result 1. We replicate the main quantitative and qualitative findings of previous experiments using the PL implementation. There is significant overdissipation, and effort levels are distributed across the entire strategy space.

Support. Our baseline treatment $P L$ involving linear costs and a probabilistic awarding of the full surplus represents by far the most common implementation of the Tullock model in experimental studies. To establish that we replicate the main results in this setting, we compare our data with the data reported in Sheremeta (2010b), as the instructions and procedures used in both studies are similar. ${ }^{3}$ The experiments differ in the subject pool (undergraduate students at Purdue University in the United States versus students at the University of East Anglia in England) and the number of experimental francs in the endowment and value of the prize (120 versus 80$)$. The substantive difference in our procedures was the use of an explicit table in the instructions summarizing the cost of each level of effort.

[Figure 1 about here.]

\footnotetext{
${ }^{2}$ The instructions are available in Appendix A.

${ }^{3}$ Similar qualitative results on overdissipation and heterogeneity in behavior can be found in, for example, Davis and Reilly (1998); Lim et al. (2011); Potters et al. (1998); Sheremeta (2010a, 2011); Sheremeta and Zhang (2010).
} 
Figure 1 sets the histogram of the chosen effort levels in our $P L$ sessions against those in Sheremeta (2010b), where we have renormalized all effort levels in Sheremeta (2010b)'s [0, 120] interval onto our $[0,80]$ scale. We replicate the general qualitative shape of the distribution of effort levels, most notably that the mode of the distribution occurs at effort levels near zero. Quantitatively, our data demonstrate slightly higher effort levels both in terms of means (26.2, versus Sheremeta (2010b)'s 22.7) and medians (20 versus 15.3).

[Figure 2 about here.]

We now turn to comparing the baseline treatment $P L$ to the other three treatments. Figure 2 displays the histograms of effort levels for each treatment. The histograms reveal that both factors in the experimental design have a clear qualitative effect on the distribution of effort choices. Subjects do respond both to changes in the allocation rule and changes in the cost structure, indicating both are taken into account in the subjects' decision-making processes.

[Table 1 about here.]

Table 1 displays summary statistics on the distribution of efforts by treatment. At the level of point estimates of the location parameters (mean and median), the share rule has the expected effect: efforts decrease on average under the share rule both with linear and convex costs. The treatment effect of using the convex cost structure relative to linear is not as clear. With the share rule, convex costs decrease mean and median effort levels; however, with the probability rule, convex costs appear to increase the mean and median effort level. As expected, convex costs reduce dispersion in effort.

[Figure 3 about here.]

The average costs of effort in Table 1 imply that on average participants were making losses in $P L, P C$, and $S L$. As this implies that there were opportunties in the experiment for participants to significantly increase their earnings, a next question is whether there is any evidence of a change in behavior based on experience over time in the experiment. Figure 3 displays the time series of average effort levels for each of the four treatments. There is an impression of modest decreases in the average effort over time, but not of strong convergence towards the equilibrium prediction. In addition, the ordering of the treatments from Table 1 in terms of average efforts is observed, in general, throughout the experiment.

We formalize the analysis of treatment effects and time trends on average dissipation levels by estimating a panel regression model

$$
o_{i t}=e_{i t}-15=\beta_{0}+\beta_{1} P+\beta_{2} C+\beta_{3} t+u_{i}+\varepsilon_{i t} .
$$


The dependent variable, $o_{i t}$, is the overdissipation relative to the Nash equilibrium prediction. We include indicator variables for whether the probability rule is employed, $P=1$, and whether the convex cost structure is employed, $C=1$. We use a random-effects error structure by subject, to account for the multiple decisions made by individual subjects. Standard errors are clustered at the session level to account for session effects.

[Table 2 about here.]

Table 2 reports the estimation results of the models. We report five specifications. Specification (1) pools all available data. Specifications (2) through (5) focus on comparing treatment pairs which differ only in one dimension. Based on these regressions, we can formally support the following results on average overdissipation levels.

Result 2. The share rule significantly reduces average overdissipation when using convex costs. When using linear costs, the share and probability rules are not significantly different.

Support. In specification (2) comparing $P C$ and $S C$, average overdissipation is higher by 11.27 in $P C$. This is significant at the $1 \%$ level. Further, in magnitudes, $S C$ exceeds the equilibrium prediction by only 5.63; $P C$ is three times farther, in effort choice terms, from the equilibrium. Turning to specification (3), average overdissipation is 3.19 higher in $P L$ than $S L$, although the difference is not statistically significant. It is also small relative to the baseline overdissipation of 12.34 in $S L$.

Result 3. When using the share rule, overdissipation is significantly lower with convex costs. When using the probability rule, the difference between linear and convex costs is not significantly different.

Support. In specification (5) comparing $S C$ and $S L$, convex costs significantly decrease effort levels, with overdissipation in $S C$ being only $43 \%$ of that in $S L$. This result is intuitive given that the convex cost function provides sharper incentives against high effort levels. Comparing the probability rule treatments $P C$ and $P L$, however, the direction of the comparison goes the other way. The average efforts are higher with convex costs, although the size of the effect is not statistically significant and is relatively small compared to the baseline overdissipation observed in $P L$.

Result 4. There is evidence of learning and adjustment over time towards lower overdissipation in all treatments at the aggregate level.

Support. In all five regression model specifications, we find that the coefficient on the period number is negative in sign, statistically significant at the $1 \%$ level, and consistent in magnitude, ranging from -0.19 to -0.28 . 
While the aggregate effects are indeed relevant, the more striking feature of Figure 2 is that it reveals that qualitative properties of the distribution of efforts vary across treatments. In all cases, we replicate the stylized fact that the point prediction of Nash equilibrium does not capture the richness of observed behavior. We now turn to understanding more closely the mechanisms that generate these effort distributions, which in turn ultimately determine the aggregate performance of the contests.

Figure 2 pooled all effort choices of all subjects across all sessions for each treatment. Based on the results of the regressions in Table 2, on aggregate there is some evidence of learning and adjustment over time. To focus on behavior after subjects have had a chance to understand the rules of the game and anticipate the possible behavior of others in their cohort, we look at the second half of the experiment (periods 16 through 30). Furthermore, we are interested in decomposing how much of the variation in efforts is across subjects versus within subjects.

[Figure 4 about here.]

Figure 4 presents, for each subject in each treatment, a boxplot capturing the distribution of effort choices over the last half of the experiment. Subjects are ordered by increasing median effort choices, which are indicated by diamonds. Therefore, by focusing on the diamonds, one can read off the cumulative empirical distribution of the median choices across subjects, while by focusing on the boxplots themselves, one can get a sense of the degree of within-subject variation in behavior.

Result 5. The share rule reduces variability both within subjects and across subjects.

Support. First comparing $P L$ and $S L$ and focusing on across-subjects variability, the distribution of median choices crosses the equilibrium value of 15 at the same point. On either side, the distribution of medians in $S L$ is closer to the equilibrium value than in $P L$. Comparing $P C$ with $S C$ the effect is even more striking; almost all subjects in $S C$ have median choices within 5 units of effort of the equilibrium, while in $P C$ the median effort choices are distributed across the strategy set.

Within-subjects, in both the linear and convex cases, the size of the boxes for subjects tend to be smaller in $S L$ than $P L$ and $S C$ than $P C$, with again the effect being most striking when comparing $P C$ and $S C$.

Result 6. Variability both within subjects and across subjects is smaller with convex costs than with linear costs.

Support. First comparing $S L$ and $S C$, it is clear that median efforts cluster more closely to the equilibrium value in $S C$ than $S L$, and that the amount of variability within subjects is much smaller in $S C$. 
Comparing $P L$ and $P C$, the distribution of median efforts is less dispersed in the convex cost treatment. Within-subject variation is also less prominent in $P C$. What distinguishes the probability rule from the share rule, and begins to shed light on the unexpected comparative static on mean overdissipation between $P L$ and $P C$, is the location in the strategy space where $P C$ gathers effort choices. Rather than gathering relatively close to Nash, as in $S C$, in $P C$ most subjects settle on efforts in between 20 and 30. Further, this cadre of subjects with median choices in $[20,30]$ in $P C$ also exhibit the least variability in effort levels in that treatment. That is to say, it is not the case that these subjects have median effort levels in that range because they are exploring the full strategy space or picking at random.

\section{[Figure 5 about here.]}

Nash equilibrium predictions rest crucially on the assumptions that players have correct beliefs about the distributions of strategy choices, and, given these beliefs, choose responses which maximize their own payoffs. The nondegenerate distributions of effort levels observed in contests provide prima facie evidence that indeed subjects are not best-responding expected-earnings maximizers who have correct beliefs about the behavior of other participants in their cohort. While our rejection of point predictions of Nash equilibrium is neither novel nor surprising, our design allows us to look more closely at the Nash equilibrium assumptions to infer whether and how they fail.

In our design, subjects get feedback about the overall spending in their group in each period. Therefore, we begin by supposing that subjects have at least an approximate sense of the distribution of effort levels being chosen, therefore retaining the correct beliefs assumption, while relaxing the assumption of expected earnings maximization. One commonly-used model which captures these assumptions is the quantal response equilibrium (QRE) of McKelvey and Palfrey (1995). In a QRE, a player evaluates the expected payoff of each strategy choice inclusive of an additive noise term. We follow the standard in random-utility models by using the logit form of QRE. This form has one free parameter, $\lambda \in[0, \infty)$, which is a precision parameter; larger values of $\lambda$ correspond to a smaller variance in the noise term in payoff evaluation.

To take logit QRE to the data, we first again focus on the last 15 periods of the experiment, both because QRE assumes players have accurate beliefs about the play of others, and because we treat QRE as a static concept, so we avoid a confound with any early-period learning and adjustment. We estimate $\lambda$ by maximum likelihood, pooling across all subjects across all sessions. ${ }^{4}$ Figure 5 displays the QRE fits superimposed over the histogram of choices, and reports the corresponding values of $\lambda$ for each.

\footnotetext{
${ }^{4}$ As in all logit models, $\lambda$ is cardinal, having units equal to the unit of measurement of payoffs. To facilitate comparison with other papers reporting logit QRE estimates, we express $\lambda$ in units of US dollars, using the exchange rate $£ 1=\$ 1.60$ in force at the time of the experiments.
} 
Result 7. Logit QRE organizes behavior in share rule treatments well, particularly in conjunction with convex costs.

Support. The QRE fit for $S C$ has $\lambda=2.488$, which indicates a high degree of precision in best responses. ${ }^{5}$ The qualitative fit of the distribution is in very close agreement with the data. The $S L$ fit also tracks the qualitative distribution of the data; the estimated $\lambda=0.807$ remains modestly higher than previously-reported figures. The one feature QRE does not account for is the frequency of choices of 80 in $S L$. Almost all of these observations arise from one subject (see Figure 4). ${ }^{6}$

Since in our design information about the play of other participants is the same between the probability $(P L$ and $P C$ ) and share $(S L$ and $S C$ ) treatments, the inferior performance of QRE in the probability rule treatments cannot be attributed to incorrect beliefs about others' play, per se. However, a further implication of the share rule is that feedback about payoff implications of behavior is received without noise, whereas payoffs in the probability rule have a substantial random component. Determining an expected-earnings maximizing best response is more difficult under the probability rule. It is also possible that share rule treatments result in more consistent behavior because share rule eliminates several motivations that may enter into decision-making heuristics of participants in probability rule treatments, such as risk, loss aversion and a motivation to "win" the contest.

The QRE performs even better when we further introduce convex costs. As illustrated in the distributions of Figure 4 convex costs eliminate many of the very aggressive effort choices compared to linear treatments. This is not surprising, since the introduction of the convex cost structure implies that any effort level above 49 necessarily results in negative earnings, even if the contest is won. The effect of convex costs is especially strong when comparing treatments $S L$ and $S C$. However, when comparing treatments $P L$ and $P C$, convex costs have two effects. On the one hand, convex costs eliminate high effort choices, but on the other hand, this has a knock-on strategic effect; as the most aggressive effort choices are reined in, it now becomes more attractive in payoff terms to choose higher effort levels. Therefore, while in $P L 8$ of the 36 subjects have median choices below 1, meaning they choose not to enter the contest a majority of the time, similar behavior is not observed in $P C$. Instead, most participants make effort choices in the interval between 20 and 30. In $P C$, the breakeven strategy, measured against the empirical distribution of effort levels, is 24 . Therefore, the cluster of subjects in $P C$ in the interval between 20 and 30 are, to a first approximation, playing the strategy which maximizes their chances of winning subject to breaking even on average.

\footnotetext{
${ }^{5}$ For comparison, Lim et al. (2011) report $\lambda \approx 0.57$ for four-player contests, also using US dollars as the unit.

${ }^{6}$ Augmenting the QRE model to incorporate a different behavioral type which always chooses 80 does not change the conclusions significantly.
} 


\section{Discussion}

Experimental studies of lottery contests find both overdissipation and overspreading. A number of studies suggest that overdissipation in contests can be explained by noise and errors, judgmental biases, a non-monetary utility of winning, and an evolutionary stable behavior. Overspreading is usually attributed to subjects heterogeneous preferences towards losses, risk, spitefulness, and preferences towards winning.

In this study, we show how features of the contest environment which do not change the Nash equilibrium prediction nevertheless have significant implications for both overdissipation and overspreading in the contest. Specifically, in a two-by-two design, we investigate the effects of sharing the prize proportionally and of a convex cost function, while holding fixed the Nash equilibrium. We find that the share rule results in average efforts closer to the Nash prediction, lower variation in individual efforts, and convergence of the distribution of individual efforts towards Nash over time. Combining the share rule with a convex cost function further enhances these results.

The findings of our study can explain several puzzles in the literature. First, experimental studies on rank-order tournaments (Lazear and Rosen, 1981) find that there is almost no overdissipation and average efforts are usually consistent with Nash equilibrium (Bull et al., 1987). This is in sharp contrast to the findings from lottery contests. ${ }^{7}$ Our results suggest that this disparity can be explained by the fact that experiments on rank-order tournaments employ convex cost of effort - which, in that setting, is often needed to obtain a Nash equilibrium in pure strategies while experiments on lottery contests employ linear cost of effort. Specifically, we find significant overdissipation with linear costs (as in most experiments on lottery contests) but it disappears when costs are convex.

The current results also help to clarify why a subset of studies on rent-seeking contests, including Shogren and Baik (1991), Baik et al. (1999), and Linster et al. (2001) find little to no overdissipation. While the majority of experimental studies employ lottery rule to determine the winner of the contest (Sheremeta et al., 2012), the three aforementioned studies employ a share rule. For example, Shogren and Baik (1991) employ the share rule and find that subjects learn to play Nash equilibrium in the final periods of the experiment. The results of our experiment show that the share rule results in average efforts closer to the Nash equilibrium prediction, while the probability rule results in overdissipation.

Some contest settings arise naturally and are not amenable to design in the implementation of the prize allocation or cost rules. When design is possible, our results provide guidance on design from behavioral principles. The experimental literature has shown that behavior in games can vary as a function of design parameters, even when the Nash equilibrium is independent of those

\footnotetext{
${ }^{7}$ For a review see Sheremeta et al. (2012).
} 
parameters (see the elegant review of Goeree and Holt (2001) for a selection of examples). In contests with the probability rule and linear costs, behavior does not appear to be well-organized by equilibrium, even in a model which admits individual heterogeneity in preferences. Effective design of a contest game in which behavior in the baseline is inconsistent with equilibrium requires an understanding of the drivers of non-equilibrium play. Our results in the $P C$ treatment illustrate this. An obvious hypothesis would be that making very aggressive effort choices prohibitively expensive would rein in aggressive play, and, indeed, this is observed in our data. But there appears to be a knock-on effect at work: by eliminating this aggressive play, entry into the contest becomes more attractive; participants who might otherwise sit out a contest in the face of aggressive coplayers now find it worthwhile to choose positive levels of effort. These effects operate in opposite directions, and in our data we find that the effect of increased participation is at least that of the reined-in aggressive players. Our results, then, illustrate that work on design in contests, in the lab and the field, should be informed by an account of the determinants of (non-equilibrium) behavior.

\section{References}

W. Amaldoss and A. Rapoport. Excessive expenditure in two-stage contests: Theory and experimental evidence. In F. Columbus, editor, Game Theory: Strategies, Equilibria, and Theorems. Nova Science Publishers, Hauppauge, NY, 2009.

E. Baharad and S. Nitzan. Contest efforts in light of behavioral considerations. Economic Journal, 188:2047-2059, 2008.

K. H. Baik, T. L. Cherry, S. Kroll, and J. F. Shogren. Endogenous timing in a gaming tournament. Theory and Decision, 47:1-21, 1999.

C. Bull, A. Schotter, and K. Weigelt. Tournaments and piece rates: An experimental study. Journal of Political Economy, 95:1-33, 1987.

S. H. Chew. A generalization of the quasilinear mean with applications to the measurement of income inequality and decision theory resolving the Allais paradox. Econometrica, 51:10651092, 1983.

D. Davis and R. Reilly. Do many cooks always spoil the stew? An experimental analysis of rent-seeking and the role of a strategic buyer. Public Choice, 95:89-115, 1998.

U. Fischbacher. z-Tree: Zurich Toolbox for Ready-Made Economic Experiments. Experimental Economics, 10:171-178, 2007. 
S. Georganas, D. Levin, and P. McGee. Do irrelevant payoffs affect behavior when dominant strategy is available: Experimental evidence from second-price auctions. Working paper, 2011.

G. Gigrenzer and R. Selten. Bounded Rationality: The Adaptive Toolbox. MIT Press, 2001.

J. Goeree, C. Holt, and T. Palfrey. Quantal response equilibrium and overbidding in private-value auctions. Journal of Economic Theory, 104:247-272, 2002.

J. K. Goeree and C. A. Holt. Ten little treasures of game theory and ten intuitive contradictions. American Economic Review, 91(5):1402-1422, 2001.

G. W. Harrison. Theory and misbehavior of first-price auctions. American Economic Review, 79: 749-762, 1989.

B. Herrman and H. Orzen. The appearance of homo rivalis: Social preferences and the nature of rent-seeking. Working paper, University of Nottingham, 2008.

A. L. Hillman and E. Katz. Risk-averse rent seekrs and the social cost of monopoly power. Economic Journal, 94:104-110, 1984.

D. Kahneman and A. Tversky. Prospect theory: An analysis of decision under risk. Econometrica, 47:263-291, 1979.

X. Kong. Loss aversion and rent-seeking: An experimental study. Working paper, University of Nottingham, 2008.

E. P. Lazear and S. Rosen. Rank-order tournaments as optimum labor contracts. Journal of Political Economy, 89:841-864, 1981.

W. Lim, A. Matros, and T. L. Turocy. Bounded rationality and group size in Tullock contests: Experimental evidence. Working paper, 2011.

B. G. Linster, R. L. Fullerton, M. McKee, and S. Slate. Rent-seeking models of international competition: An experimental investigation. Defence and Peace Econonomics, 12:285-302, 2001.

S. D. Mago, A. C. Savikhin, and R. M. Sheremeta. Facing your oppnents: Social identification and information feedback in contests. ESI Working Paper, 2012.

R. D. McKelvey and T. R. Palfrey. Quantal response equilibrium for normal form games. Games and Economic Behavior, 10:6-38, 1995. 
E. L. Millner and M. D. Pratt. An experimental investigation of efficient rent-seeking. Public Choice, 62:139-151, 1989.

E. L. Millner and M. D. Pratt. Risk aversion and rent-seeking: An extension and some experimental evidence. Public Choice, 69:81-92, 1991.

W. Müller and A. Schotter. Workaholics and dropouts in organizations. Journal of the European Economic Association, 8:717-743, 2010.

J. C. Potters, C. G. de Vries, and F. van Winden. An experimental examination of rational rent seeking. European Journal of Political Economy, 14:783-800, 1998.

J. W. Pratt. Risk aversion in the small and in the large. Econometrica, 32:122-136, 1964.

C. R. Price and R. M. Sheremeta. Endowment effects in contests. Economics Letters, 111:217-219, 2011.

J. Quiggin. A theory of anticipated utility. Journal of Economic Behavior and Organization, 3: 323-343, 1982.

A. Rubenstein. Modeling Bounded Rationality. MIT Press, 1998.

D. Schmidt, R. Schupp, and J. Walker. Resource allocation contests: Experimental evidence. Working paper, Indiana University, 2005.

R. M. Sheremeta. Expenditures and information disclosure in two-stage political contests. Journal of Conflict Resolution, 54:771-798, 2010a.

R. M. Sheremeta. Experimental comparison of multi-stage and one-stage contests. Games and Economic Behavior, 68:731-747, 2010b.

R. M. Sheremeta. Contest design: An experimental investigation. Economic Inquiry, 49:573-590, 2011.

R. M. Sheremeta and J. Zhang. Can groups solve the problem of over-bidding in contests? Social Choice and Welfare, 35:175-197, 2010.

R. M. Sheremeta, E. Dechenaux, and D. Kovenock. A survey of experimental research on contests, all-pay auctions, and tournaments. ESI Working Paper, 2012.

J. F. Shogren and K. H. Baik. Reexamining efficient rent-seeking in laboratory markets. Public Choice, 69:69-79, 1991. 
H. Simon. Models of Bounded Rationality. MIT Press, 1992.

S. Skaperdas and L. Gan. Risk aversion in contests. Economic Journal, 105:951-962, 1995.

F. Szidarovszky and K. Okuguchi. On the existence and uniqueness of pure Nash equilibrium in rent-seeking games. Games and Economic Behavior, 18:135-140, 1997.

G. Tullock. Efficient rent seeking. In J. M. Buchanan, R. D. Tollison, and G. Tullock, editors, Toward a theory of the rent-seeking society, pages 97-112. Texas A\&M University Press, College Station, TX, 1980.

A. Tversky and D. Kahneman. Advances in prospect theory: Cumulative representation of uncertainty. Journal of Risk and Uncertainty, 5:297-323, 1992.

K. Wärneryd. The evolution of preferences for conflict. Economics Letters, 116:102-104, 2012.

N. T. Wilcox. 'Stochastically more risk averse:' A contextual theory of stochastic discrete choice under risk. Journal of Econometrics, 162:89-104, 2011.

W. Wright. Cognitive information processing biases: Implications for producers and users of financial information. Decision Sciences, 11:284-298, 1980.

\section{A Instructions (not for publication)}

We present as a baseline the instructions for convex costs with each rule. Relative to these instructions, the only change for linear costs was the formula for the cost of a bid, and the corresopnding bid cost table.

\section{$P C$ treatment}

\section{GENERAL INSTRUCTIONS}

This is an experiment in the economics of strategic decision making. Various research agencies have provided funds for this research. The instructions are simple. If you follow them closely and make appropriate decisions, you can earn an appreciable amount of money.

The currency used in the experiment is francs. Francs will be converted to British Pounds at a rate of 20 francs to 1 pound. You have already received a $£ 15.00$ participation fee. At the end of todays experiment, you will be paid in private and in cash. 12 participants are in todays experiment. 
It is very important that you remain silent and do not look at other peoples work. If you have any questions, or need assistance of any kind, please raise your hand and an experimenter will come to you. If you talk, laugh, exclaim out loud, etc., you will be asked to leave and you will not be paid. We expect and appreciate your cooperation.

\section{YOUR DECISION}

The experiment consists of $\mathbf{3 0}$ decision-making periods. At the beginning of each period, you will be randomly and anonymously placed into a group of $\mathbf{4}$ participants. The composition of your group will be changed randomly every period. Each period, you may bid for an $\mathbf{8 0}$ francs reward. You may bid any number between $\mathbf{0}$ and $\mathbf{8 0}$ (including 0.1 decimal points). An example of your decision screen is shown below.

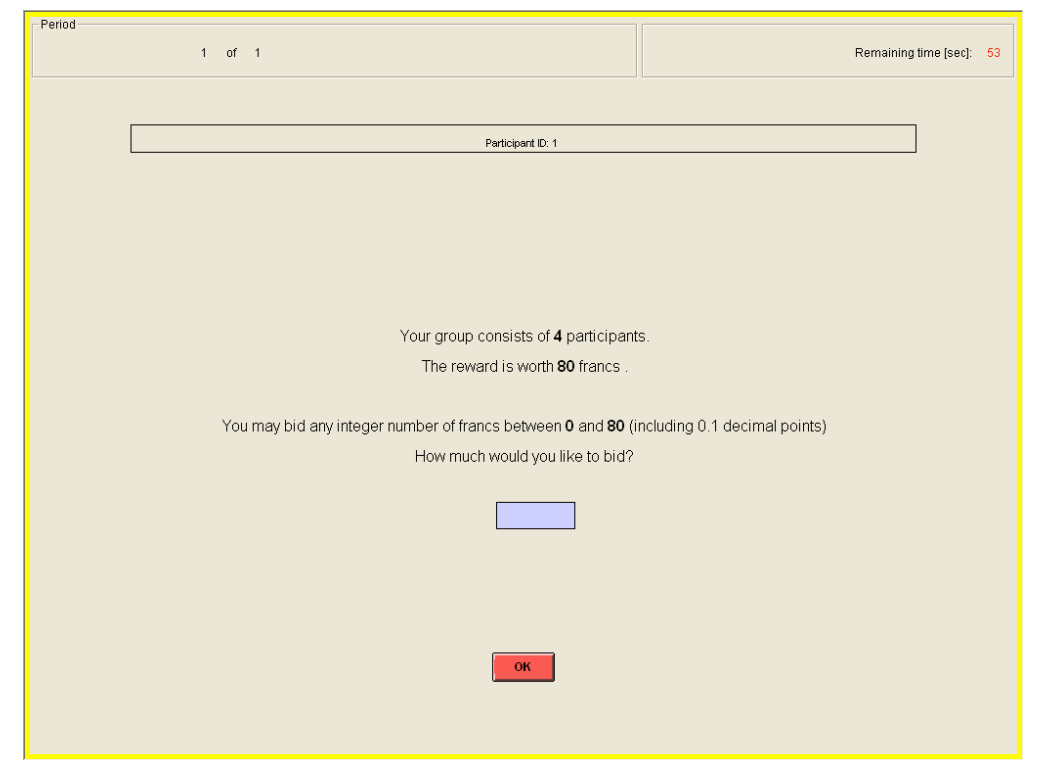

\section{YOUR EARNINGS}

For each bid there is an associated cost. A table is attached to these instructions: each possible bid is given in column $\mathrm{A}$, and its cost is given in column $\mathrm{B}$. Note that as bids rise from 0 to 80 , costs rise. The cost of a bid can be also calculated using the following formula:

$$
\text { Cost of your bid }=\frac{(\text { Your bid })^{2}}{30} \text {. }
$$

The more you bid, the more likely you are to receive the reward. The more the other participants in your group bid, the less likely you are to receive the reward. Specifically, your chance of 
receiving the reward is given by your bid divided by the sum of all 4 bids in your group:

$$
\text { Chance of receiving the reward }=\frac{\text { Your bid }}{\text { Sum of all } 4 \text { bids in your group }} \text {. }
$$

You can consider the amounts of the bids to be equivalent to numbers of lottery tickets. The computer will draw one ticket from those entered by you and the other participants, and assign the reward to one of the participants through a random draw. If you receive the reward, your earnings for the period are equal to the reward of 80 francs minus the cost of your bid. If you do not receive the reward, your earnings for the period are equal to 0 francs minus the cost of your bid. In other words, your earnings are:

If you receive the award: Earnings $=$ Reward - Cost of your bid $=80$ - Cost of your bid If you do not receive the award: Earnings $=0$ - Cost of your bid

\section{AN EXAMPLE}

Lets say participant 1 bids 10 francs, participant 2 bids 15 francs, participant 3 bids 0 francs, and participant 4 bids 40 francs. Therefore, the computer assigns 10 lottery tickets to participant 1, 15 lottery tickets to participant 2, 0 lottery tickets to participant 3, and 40 lottery tickets for participant 4. Then the computer randomly draws one lottery ticket out of $65(10+15+0+40)$. As you can see, participant 4 has the highest chance of receiving the reward: $0.62=\mathbf{4 0 / 6 5}$. Participant 1 has a $\mathbf{0 . 1 5}=\mathbf{1 0} / \mathbf{6 5}$ chance, participant 2 has a $\mathbf{0 . 2 3}=\mathbf{1 5 / 6 5}$ chance, and participant 3 has a $0=0 / 65$ chance of receiving the reward.

Assume that the computer assigns the reward to participant 4, then the earnings of participant 4 for the period are $26.67=80-53.33$, since the reward is 80 francs and the cost of bid of 40 is 53.33 as shown on your Cost of Bid table. Similarly, the earnings of participant 1 are $-3.33=0$ 3.33, participant 2 are $-7.5=0-7.5$, and participant 3 are $0=0-0$.

At the end of each period, your bid, the sum of all 4 bids in your group, your reward, the cost of your bid, and your earnings for the period are reported on the outcome screen as shown below. Once the outcome screen is displayed you should record your results for the period on your Personal Record Sheet under the appropriate heading. 


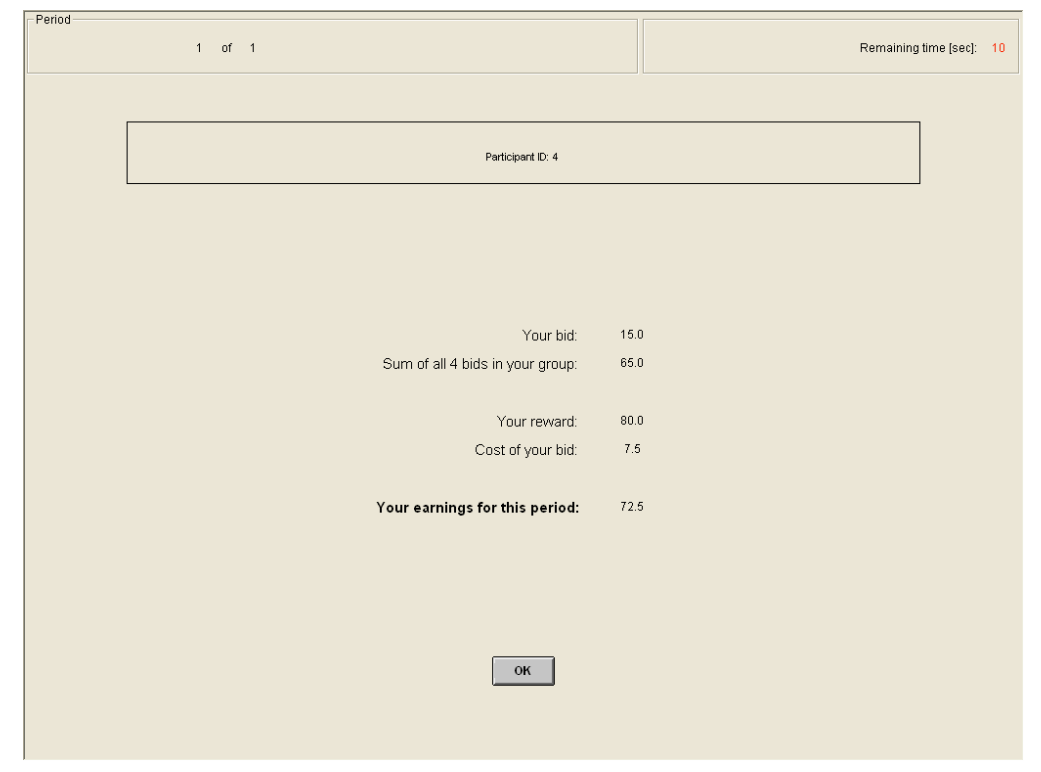

\section{IMPORTANT NOTES}

You will not be told which of the participants in this room are assigned to which group. At the beginning of each period you will be randomly re-grouped with other three participants to form a 4-person group.

For calculation purposes, you can use the "Calculator" button at the lower left side of your screen. A calculator will appear in your screen after clicking the button.

At the end of the experiment we will randomly choose 5 of the $\mathbf{3 0}$ periods for actual payment for this experiment using a computer program. You will sum the total earnings for these 5 periods and convert them to a British pound payment.

\section{Are there any questions?}

\section{$S C$ treatment}

\section{GENERAL INSTRUCTIONS}

This is an experiment in the economics of strategic decision making. Various research agencies have provided funds for this research. The instructions are simple. If you follow them closely and make appropriate decisions, you can earn an appreciable amount of money.

The currency used in the experiment is francs. Francs will be converted to British Pounds at a rate of 20 francs to 1 pound. You have already received a $£ \mathbf{1 5 . 0 0}$ participation fee. At the end of todays experiment, you will be paid in private and in cash. 12 participants are in todays experiment.

It is very important that you remain silent and do not look at other peoples work. If you have 
any questions, or need assistance of any kind, please raise your hand and an experimenter will come to you. If you talk, laugh, exclaim out loud, etc., you will be asked to leave and you will not be paid. We expect and appreciate your cooperation.

\section{YOUR DECISION}

The experiment consists of $\mathbf{3 0}$ decision-making periods. At the beginning of each period, you will be randomly and anonymously placed into a group of $\mathbf{4}$ participants. The composition of your group will be changed randomly every period. Each period, you may bid for a share of an 80 francs reward. You may bid any number between $\mathbf{0}$ and $\mathbf{8 0}$ (including 0.1 decimal points). An example of your decision screen is shown below.

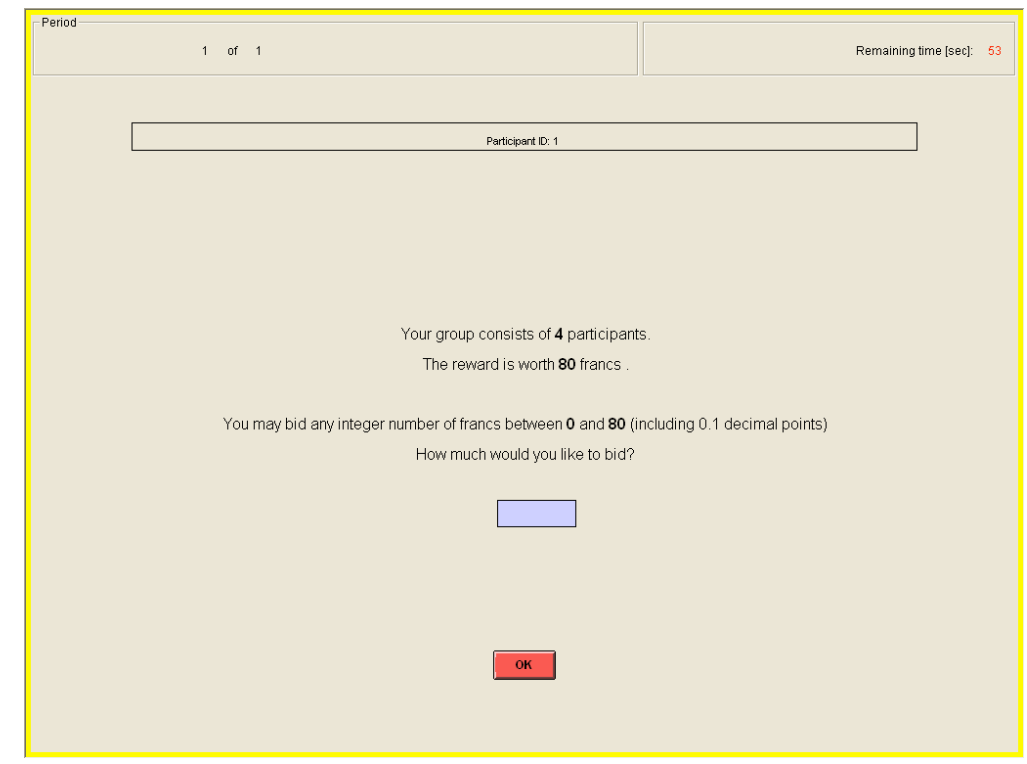

\section{YOUR EARNINGS}

For each bid there is an associated cost. A table is attached to these instructions: each possible bid is given in column $\mathrm{A}$, and its cost is given in column $\mathrm{B}$. Note that as bids rise from 0 to 80 , costs rise. The cost of a bid can be also calculated using the following formula:

$$
\text { Cost of your bid }=\frac{(\text { Your bid })^{2}}{30} \text {. }
$$

The more you bid, the higher is your share of the reward. The more the other participants in your group bid, the lower is your share of the reward. Specifically, the computer will allocate to you a share of the 80 francs reward according to your share of the sum of all 4 bids in your group. In other words, your share is: 


$$
\text { Share }=80 \times \frac{\text { Your bid }}{\text { Sum of all } 4 \text { bids in your group }}
$$

Your earnings for the preiod are equal to the share of the 80 francs reward minus the cost of your bid. In other words, your earnings are:

$$
\text { Earnings }=\text { Share }- \text { cost of your bid }
$$

\section{AN EXAMPLE}

Lets say participant 1 bids 10 francs, participant 2 bids 15 francs, participant 3 bids 0 francs, and participant 4 bids 40 francs. Then the sum of all 4 bids is $65(10+15+0+40)$. As you can see, participant 4 receives the highest share of 80 francs reward: $49.2=80 \times 40 / 65$. Participant 1 receives a share of $12.3=80 \times 10 / 65$, participant 2 receives $18.5=80 \times 15 / 65$, and participant 3 receives $0=80 \times 0 / 65$.

The earnings of participant 1 for the period are $8.97=12.3-3.33$, since the share of the reward is 12.3 and the cost of bid of 10 is 3.33 as shown on your Cost of Bid table. Similarly, the earnings of participant 2 are $11=18.5-7.5$, participant 3 are $0=0-0$, and participant 4 are $-4.1=49.2$ 53.33.

At the end of each period, your bid, the sum of all 4 bids in your group, your share, the cost of your bid, and your earnings for the period are reported on the outcome screen as shown below. Once the outcome screen is displayed you should record your results for the period on your Personal Record Sheet under the appropriate heading.

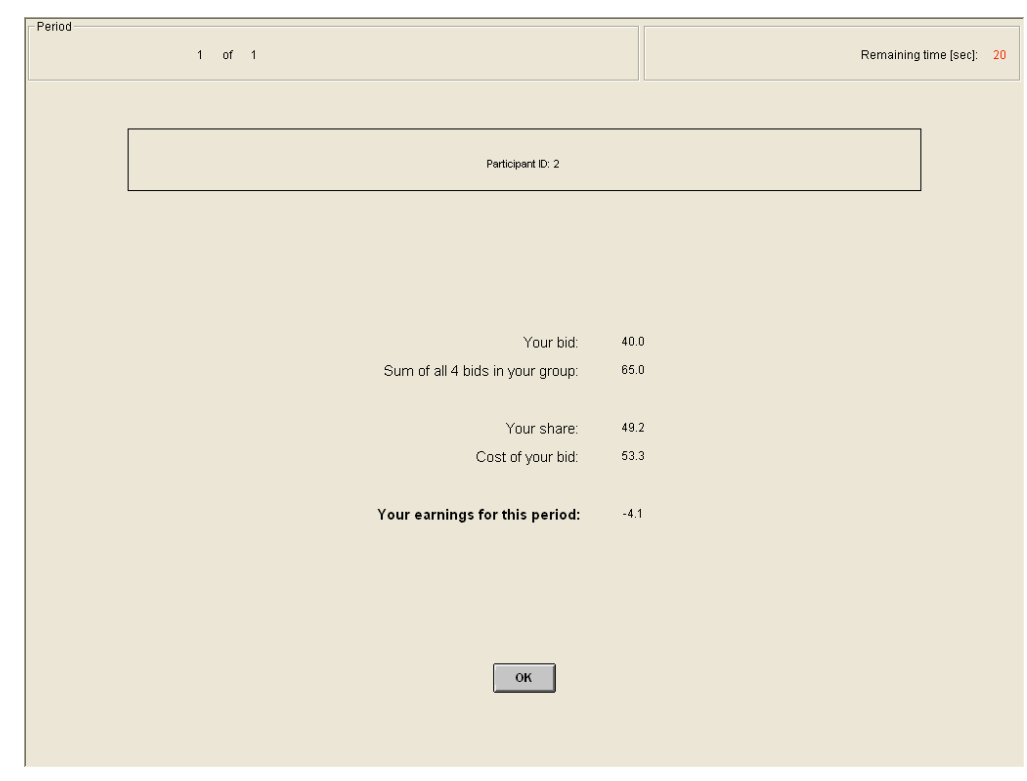




\section{Cost table (common to both treatments)}

Table - Cost of Bid

\begin{tabular}{|c|c|c|c|c|c|}
\hline Column A & Column B & Column A & Column B & Column A & Column B \\
\hline Bid & Cost of Bid & Bid & Cost of Bid & Bid & Cost of Bid \\
\hline 0 & 0.00 & 30 & 30.00 & 60 & 120.00 \\
\hline 1 & 0.03 & 31 & 32.03 & 61 & 124.03 \\
\hline 2 & 0.13 & 32 & 34.13 & 62 & 128.13 \\
\hline 3 & 0.30 & 33 & 36.30 & 63 & 132.30 \\
\hline 4 & 0.53 & 34 & 38.53 & 64 & 136.53 \\
\hline 5 & 0.83 & 35 & 40.83 & 65 & 140.83 \\
\hline 6 & 1.20 & 36 & 43.20 & 66 & 145.20 \\
\hline 7 & 1.63 & 37 & 45.63 & 67 & 149.63 \\
\hline 8 & 2.13 & 38 & 48.13 & 68 & 154.13 \\
\hline 9 & 2.70 & 39 & 50.70 & 69 & 158.70 \\
\hline 10 & 3.33 & 40 & 53.33 & 70 & 163.33 \\
\hline 11 & 4.03 & 41 & 56.03 & 71 & 168.03 \\
\hline 12 & 4.80 & 42 & 58.80 & 72 & 172.80 \\
\hline 13 & 5.63 & 43 & 61.63 & 73 & 177.63 \\
\hline 14 & 6.53 & 44 & 64.53 & 74 & 182.53 \\
\hline 15 & 7.50 & 45 & 67.50 & 75 & 187.50 \\
\hline 16 & 8.53 & 46 & 70.53 & 76 & 192.53 \\
\hline 17 & 9.63 & 47 & 73.63 & 77 & 197.63 \\
\hline 18 & 10.80 & 48 & 76.80 & 78 & 202.80 \\
\hline 19 & 12.03 & 49 & 80.03 & 79 & 208.03 \\
\hline 20 & 13.33 & 50 & 83.33 & 80 & 213.33 \\
\hline 21 & 14.70 & 51 & 86.70 & & \\
\hline 22 & 16.13 & 52 & 90.13 & & \\
\hline 23 & 17.63 & 53 & 93.63 & & \\
\hline 24 & 19.20 & 54 & 97.20 & & \\
\hline 25 & 20.83 & 55 & 100.83 & & \\
\hline 26 & 22.53 & 56 & 104.53 & & \\
\hline 27 & 24.30 & 57 & 108.30 & & \\
\hline 28 & 26.13 & 58 & 112.13 & & \\
\hline 29 & 28.03 & 59 & 116.03 & & \\
\hline
\end{tabular}




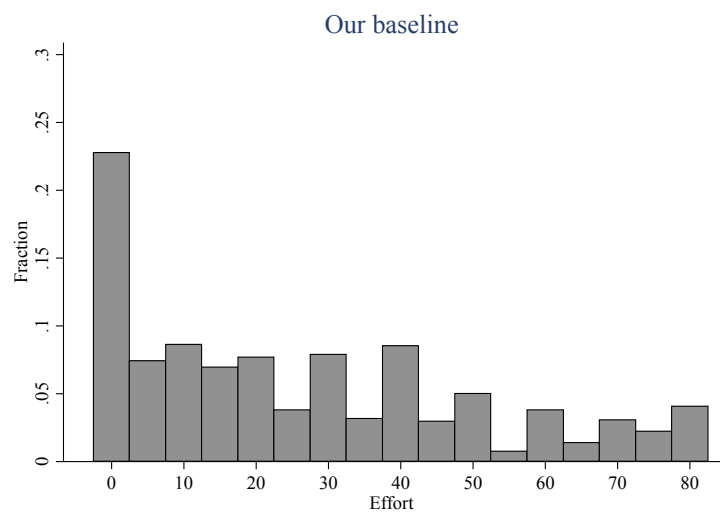

(a) Our baseline treatment $P L$

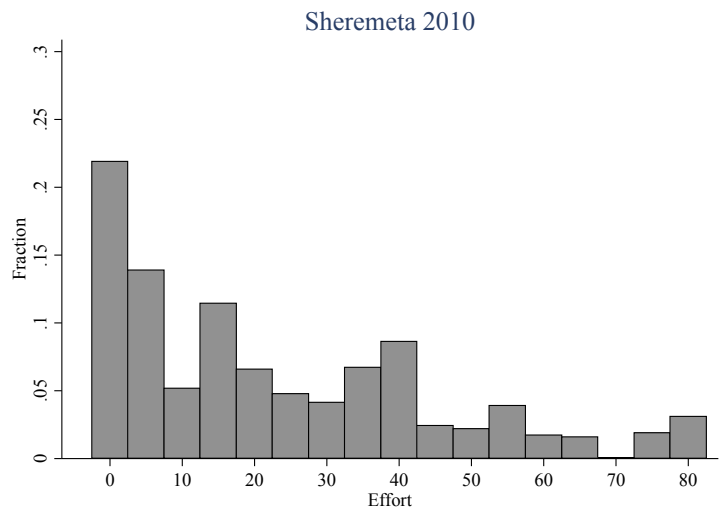

(b) Sheremeta (GEB 2010)

Figure 1: Comparison of the baseline treatment to previously-published data. Effort levels in Sheremeta (GEB 2010) rescaled to match the range in the present experiments. The baseline treatment replicates the standard stylized facts about the level and distribution of effort choices. 


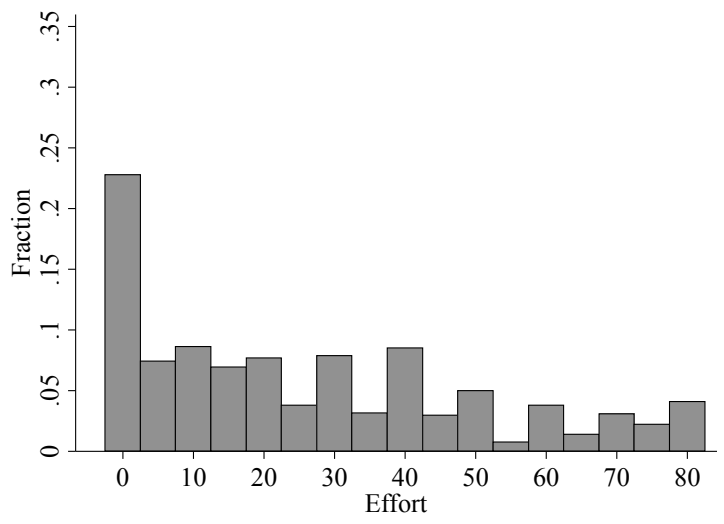

(a) $P L$

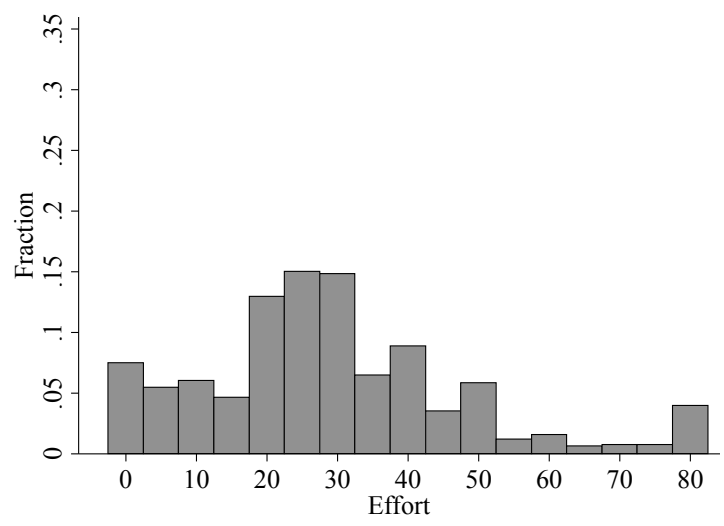

(c) $P C$

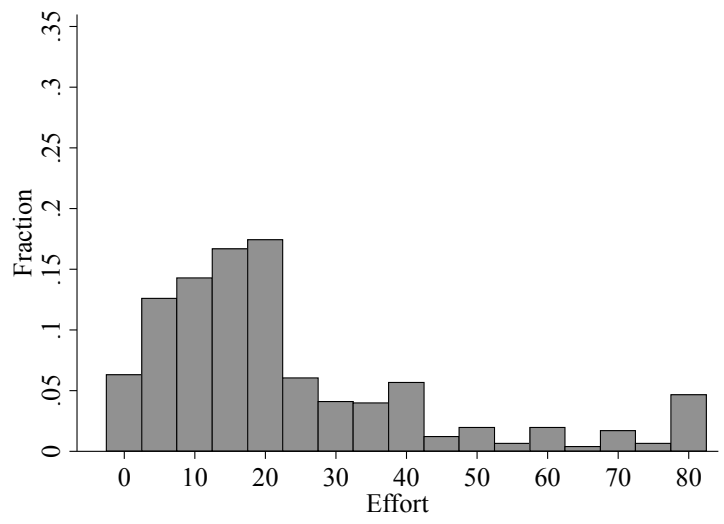

(b) $S L$

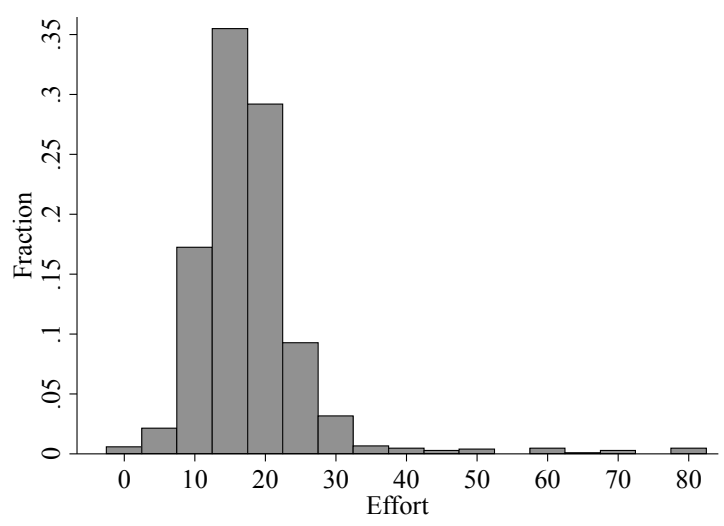

(d) $S C$

Figure 2: Distribution of effort choices for each of the four treatments, all periods. 


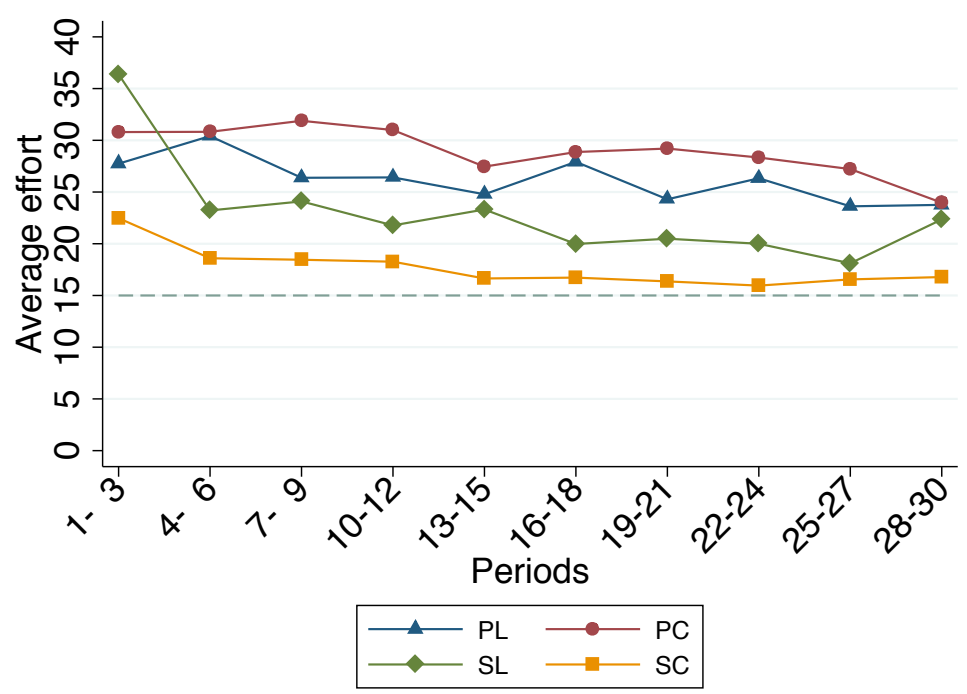

Figure 3: Average efforts over time, by treatment 


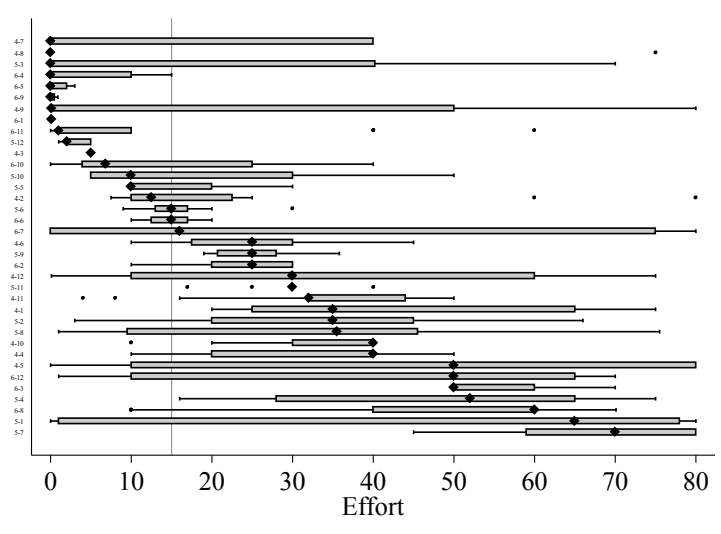

(a) $P L$

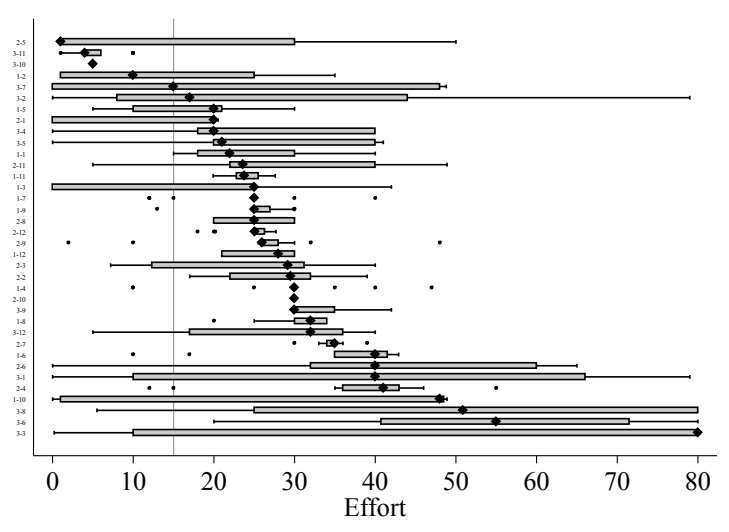

(c) $P C$

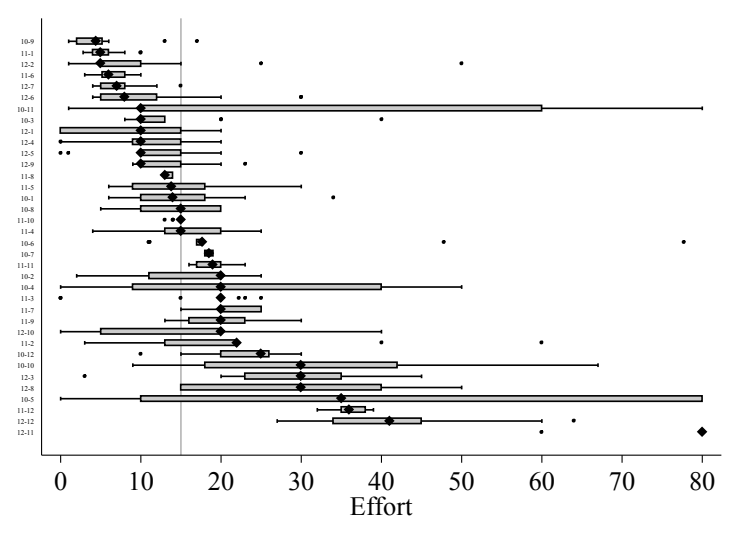

(b) $S L$

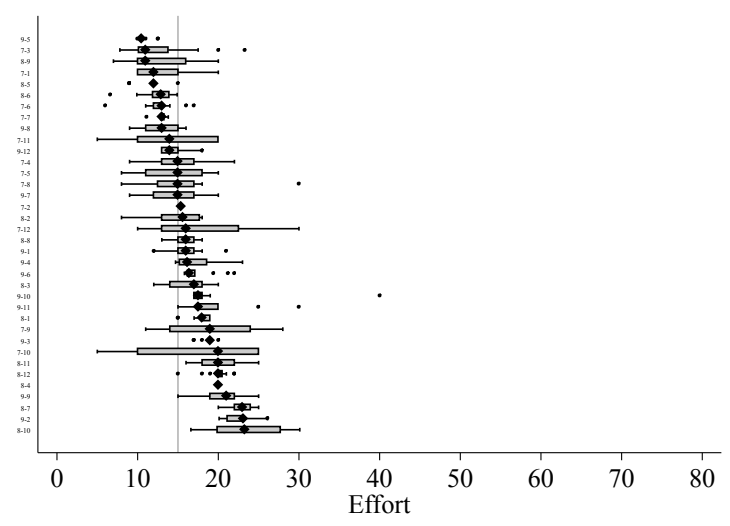

(d) $S C$

Figure 4: Boxplot of effort choices by subject, last 15 rounds. Subjects are sorted in increasing order by median effort, which are indicated by diamonds. The vertical line at an effort of 15 marks the Nash equilibrium prediction. 


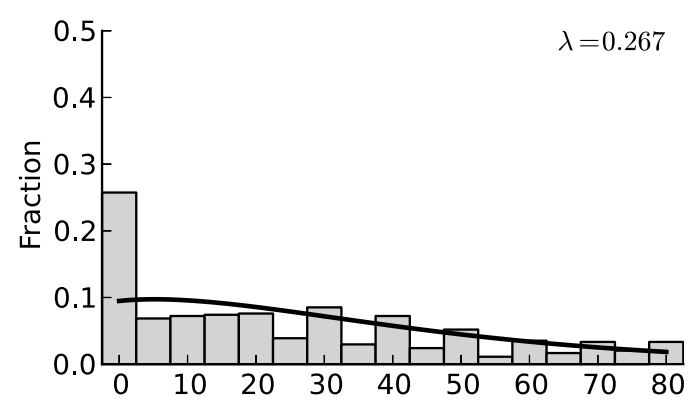

(a) $P L$

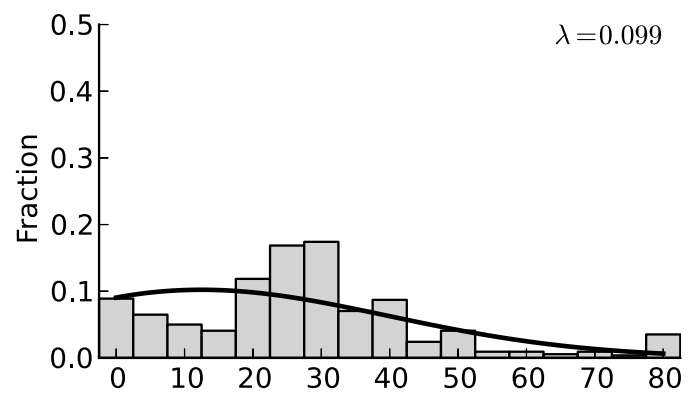

(c) $\mathrm{PC}$

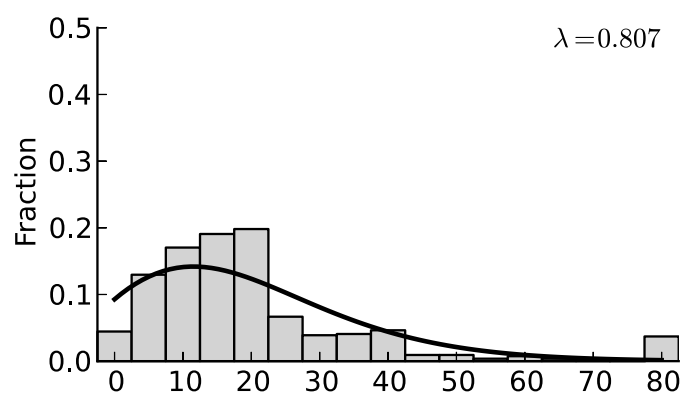

(b) $S L$

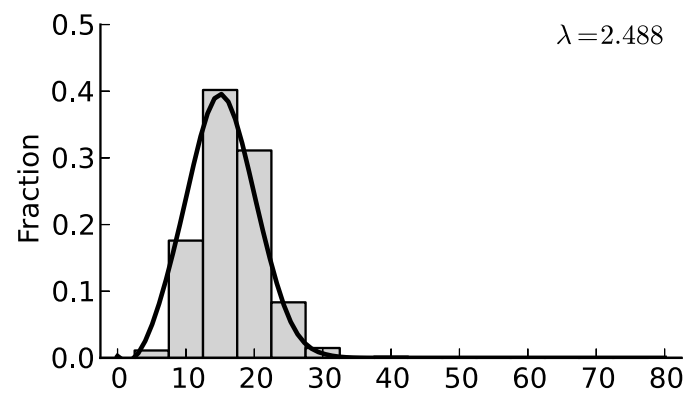

(d) $\mathrm{SC}$

Figure 5: Logit quantal response equilibrium fits to empirical distribution of effort choices, last 15 rounds. 


\begin{tabular}{|c|c|c|c|c|c|c|}
\hline \multirow[b]{2}{*}{ Effort } & \multicolumn{3}{|c|}{ Linear } & \multicolumn{3}{|c|}{ Convex } \\
\hline & Nash & $P L$ & $S L$ & Nash & $P C$ & $S C$ \\
\hline Mean & 15.0 & 26.2 & 23.0 & 15.0 & 29.0 & 17.7 \\
\hline Median & 15.0 & 20.0 & 17.5 & 15.0 & 26.0 & 16.3 \\
\hline \multirow[t]{2}{*}{ SD } & 0.0 & 24.1 & 20.0 & 0.0 & 18.6 & 8.6 \\
\hline & \multicolumn{3}{|c|}{ Linear } & \multicolumn{3}{|c|}{ Convex } \\
\hline Cost & Nash & $P L$ & $S L$ & Nash & $P C$ & $S C$ \\
\hline Mean & 15.0 & 26.2 & 23.0 & 7.5 & 39.4 & 12.9 \\
\hline Median & 15.0 & 20.0 & 17.5 & 7.5 & 22.5 & 8.8 \\
\hline SD & 0.0 & 24.1 & 20.0 & 0.0 & 48.0 & 19.9 \\
\hline
\end{tabular}

Table 1: Summary statistics on effort and cost for each of the four treatments 


\begin{tabular}{cccccc}
\hline Dependent variable, $o_{i t}=e_{i t}-15$ & All & PC and SC & PL and SL & PC and PL & SC and SL \\
\hline Specification & $(1)$ & $(2)$ & $(3)$ & $(4)$ & $(5)$ \\
\hline P (probability) & $7.23 * * *$ & $11.27 * * *$ & 3.19 & & \\
(1 if probability and 0 if share) & $(2.18)$ & $(1.89)$ & $(3.29)$ & & \\
C (convex costs) & -1.25 & & & 2.79 & $-5.29 * * *$ \\
(1 if convex and 0 if linear) & $(2.18)$ & & & $(3.16)$ & $(2.10)$ \\
period & $-0.24 * * *$ & $-0.19 * * *$ & $-0.28 * * *$ & $-0.20 * * *$ & $-0.27 * * *$ \\
(period trend) & $(0.05)$ & $(0.04)$ & $(0.09)$ & $(0.06)$ & $(0.07)$ \\
constant & $9.61 * * *$ & $5.63 * * *$ & $12.34 * * *$ & $14.23 * * *$ & $12.22 * * *$ \\
& $(2.48)$ & $(0.99)$ & $(2.81)$ & $(3.44)$ & $(2.71)$ \\
\hline Observations & 4320 & 2160 & 2160 & 2160 & 2160 \\
\hline
\end{tabular}

Table 2: Panel estimation of treatment effects. Robust standard errors in parentheses. *** indicates significance at the $1 \%$ level. All models included a random effects error structure, with the individual subject as the random effect, to account for the multiple decisions made by individual subjects. The standard errors were clustered at the session level to account for the session effects. 


\section{2}

\section{Economic Science Institute Working Papers}

12-12 Bodsky, R., Donato, D., James, K. and Porter, D. Experimental Evidence on the Properties of the California’s Cap and Trade Price Containment Reserve.

12-11 Branas-Garza, P., Espin, A. and Exadaktylos, F. Students, Volunteers and Subjects: Experiments on Social Preferences.

12-10 Klose, B. and Kovenock, D. Extremism Drives Out Moderation.

12-09 Buchanan, J. and Wilson, B. An Experiment on Protecting Intellectual Property.

12-08 Buchanan, J., Gjerstad, S. and Porter, D. Information Effects in Multi-Unit Dutch Auctions.

12-07 Price, C. and Sheremeta, R. Endowment Origin, Demographic Effects and Individual Preferences in Contests.

12-06 Magoa, S. and Sheremeta, R. Multi-Battle Contests: An experimental study.

12-05 Sheremeta, R. and Shields, T. Do Liars Believe? Beliefs and Other-Regarding Preferences in Sender-Receiver Games.

12-04 Sheremeta, R., Masters, W. and Cason. T. Winner-Take-All and Proportional-Prize Contests: Theory and experimental results.

12-03 Buchanan, J., Gjerstad, S. and Smith, V. There’s No Place Like Home.

12-02 Corgnet, B. and Rodriguez-Lara, I. Are you a Good Employee or Simply a Good Guy? Influence Costs and Contract Design.

12-01 Kimbrough, E. and Sheremeta, R. Side-Payments and the Costs of Conflict.

\section{1}

11-20 Cason, T., Savikhin, A. and Sheremeta, R. Behavioral Spillovers in Coordination Games.

11-19 Munro, D. and Rassenti, S. Combinatorial Clock Auctions: Price direction and performance.

11-18 Schniter, E., Sheremeta, R., and Sznycer, D. Restoring Damaged Trust with Promises, Atonement and Apology.

11-17 Brañas-Garza, P., and Proestakis, A. Self-discrimination: A field experiment on obesity.

11-16 Brañas-Garza, P., Bucheli, M., Paz Espinosa, M., and García-Muñoz, T. Moral Cleansing and Moral Licenses: Experimental evidence. 
11-15 Caginalp, G., Porter, D., and Hao, L. Asset Market Reactions to News: An experimental study.

11-14 Benito, J., Branas-Garz, P., Penelope Hernandez, P., and Sanchis Llopis, J. Strategic Behavior in Schelling Dynamics: A new result and experimental evidence.

11-13 Chui, M., Porter, D., Rassenti, S. and Smith, V. The Effect of Bidding Information in Ascending Auctions.

11-12 Schniter, E., Sheremeta, R. and Shields, T. Conflicted Minds: Recalibrational emotions following trust-based interaction.

11-11 Pedro Rey-Biel, P., Sheremeta, R. and Uler, N. (Bad) Luck or (Lack of) Effort?: Comparing social sharing norms between US and Europe.

11-10 Deck, C., Porter, D., and Smith, V. Double Bubbles in Assets Markets with Multiple Generations.

11-09 Kimbrough, E., Sheremeta, R., and Shields, T. Resolving Conflicts by a Random Device.

11-08 Brañas-Garza, P., García-Muñoz, T., and Hernan, R. Cognitive effort in the Beauty Contest Game.

11-07 Grether, D., Porter, D., and Shum, M. Intimidation or Impatience? Jump Bidding in On-line Ascending Automobile Auctions.

11-06 Rietz, T., Schniter, E., Sheremeta, R., and Shields, T. Trust, Reciprocity and Rules.

11-05 Corgnet, B., Hernan-Gonzalez, R., and Rassenti, S. Real Effort, Real Leisure and Real-time Supervision: Incentives and peer pressure in virtual organizations.

11-04 Corgnet, B. and Hernán-González R. Don’t Ask Me If You Will Not Listen: The dilemma of participative decision making.

11-03 Rietz, T., Sheremeta, R., Shields, T., and Smith, V. Transparency, Efficiency and the Distribution of Economic Welfare in Pass-Through Investment Trust Games.

11-02 Corgnet, B., Kujal, P. and Porter, D. The Effect of Reliability, Content and Timing of Public Announcements on Asset Trading Behavior.

11-01 Corgnet, B., Kujal, P. and Porter, D. Reaction to Public Information in Markets: How much does ambiguity matter?

\section{0}

10-23 Sheremeta, R. Perfect-Substitutes, Best-Shot, and Weakest-Link Contests between Groups.

10-22 Mago, S., Sheremeta, R., and Yates, A. Best-of-Three Contests: Experimental Evidence.

10-21 Kimbrough, E. and Sheremeta, R. Make Him an Offer He Can't Refuse: Avoiding conflicts through side payments. 
10-20 Savikhim, A. and Sheremeta, R. Visibility of Contributions and Cost of Inflation: An experiment on public goods.

10-19 Sheremeta, R. and Shields, T. Do Investors Trust or Simply Gamble?

10-18 Deck, C. and Sheremeta, R. Fight or Flight? Defending Against Sequential Attacks in the Game of Siege.

10-17 Deck, C., Lin, S. and Porter, D. Affecting Policy by Manipulating Prediction Markets: Experimental evidence.

10-16 Deck, C. and Kimbrough, E. Can Markets Save Lives? An Experimental Investigation of a Market for Organ Donations.

10-15 Deck, C., Lee, J. and Reyes, J. Personality and the Consistency of Risk Taking Behavior: Experimental Evidence.

10-14 Deck, C. and Nikiforakis, N. Perfect and Imperfect Real-Time Monitoring in a Minimum-Effort Game.

10-13 Deck, C. and Gu, J. Price Increasing Competition? Experimental Evidence.

10-12 Kovenock, D., Roberson, B., and Sheremeta, R. The Attack and Defense of Weakest-Link Networks.

10-11 Wilson, B., Jaworski, T., Schurter, K. and Smyth, A. An Experimental Economic History of Whalers' Rules of Capture.

10-10 DeScioli, P. and Wilson, B. Mine and Thine: The territorial foundations of human property.

10-09 Cason, T., Masters, W. and Sheremeta, R. Entry into Winner-Take-All and Proportional-Prize Contests: An experimental study.

10-08 Savikhin, A. and Sheremeta, R. Simultaneous Decision-Making in Competitive and Cooperative Environments.

10-07 Chowdhury, S. and Sheremeta, R. A generalized Tullock contest.

10-06 Chowdhury, S. and Sheremeta, R. The Equivalence of Contests.

10-05 Shields, T. Do Analysts Tell the Truth? Do Shareholders Listen? An Experimental Study of Analysts' Forecasts and Shareholder Reaction.

10-04 Lin, S. and Rassenti, S. Are Under- and Over-reaction the Same Matter? A Price Inertia based Account.

10-03 Lin, S. Gradual Information Diffusion and Asset Price Momentum.

10-02 Gjerstad, S. and Smith, V. Household Expenditure Cycles and Economic Cycles, 1920 - 2010. 
10-01 Dickhaut, J., Lin, S., Porter, D. and Smith, V. Durability, Re-trading and Market Performance.

\section{9}

09-11 Hazlett, T., Porter, D., and Smith, V. Radio Spectrum and the Disruptive Clarity OF Ronald Coase.

09-10 Sheremeta, R. Expenditures and Information Disclosure in Two-Stage Political Contests.

09-09 Sheremeta, R. and Zhang, J. Can Groups Solve the Problem of Over-Bidding in Contests?

09-08 Sheremeta, R. and Zhang, J. Multi-Level Trust Game with "Insider" Communication.

09-07 Price, C. and Sheremeta, R. Endowment Effects in Contests.

09-06 Cason, T., Savikhin, A. and Sheremeta, R. Cooperation Spillovers in Coordination Games.

09-05 Sheremeta, R. Contest Design: An experimental investigation.

09-04 Sheremeta, R. Experimental Comparison of Multi-Stage and One-Stage Contests.

09-03 Smith, A., Skarbek, D., and Wilson, B. Anarchy, Groups, and Conflict: An experiment on the emergence of protective associations.

09-02 Jaworski, T. and Wilson, B. Go West Young Man: Self-selection and endogenous property rights.

09-01 Gjerstad, S. Housing Market Price Tier Movements in an Expansion and Collapse.

\section{8}

08-09 Dickhaut, J., Houser, D., Aimone, J., Tila, D. and Johnson, C. High Stakes Behavior with Low Payoffs: Inducing preferences with Holt-Laury gambles.

08-08 Stecher, J., Shields, T. and Dickhaut, J. Generating Ambiguity in the Laboratory.

08-07 Stecher, J., Lunawat, R., Pronin, K. and Dickhaut, J. Decision Making and Trade without Probabilities.

08-06 Dickhaut, J., Lungu, O., Smith, V., Xin, B. and Rustichini, A. A Neuronal Mechanism of Choice.

08-05 Anctil, R., Dickhaut, J., Johnson, K., and Kanodia, C. Does Information Transparency Decrease Coordination Failure?

08-04 Tila, D. and Porter, D. Group Prediction in Information Markets With and Without Trading Information and Price Manipulation Incentives.

08-03 Thomas, C. and Wilson, B. Horizontal Product Differentiation in Auctions and Multilateral Negotiations. 
08-02 Oprea, R., Wilson, B. and Zillante, A. War of Attrition: Evidence from a laboratory experiment on market exit.

08-01 Oprea, R., Porter, D., Hibbert, C., Hanson, R. and Tila, D. Can Manipulators Mislead Prediction Market Observers? 